\title{
Kinetic study on phosphate removal from aqueous solution by biochar derived from peanut shell as renewable adsorptive media
}

\author{
K.-W. Jung • M.-J. Hwang • K.-H. Ahn • \\ Y.-S. Ok
}

Received: 31 July 2014/Revised: 13 November 2014/ Accepted: 27 January 2015/Published online: 4 February 2015

(C) Islamic Azad University (IAU) 2015

\begin{abstract}
As an alternative strategy for phosphate removal, biochar (black carbon) has characteristics superior to those of widely used adsorptive media, from both economic and environmental points of view. In this study, various types of biochar derived from oak wood, bamboo wood, maize residue, soybean stover, and peanut shell were tested for evaluation of phosphate removal. After $24 \mathrm{~h}$ of reaction time, the phosphate removal was limited (2.0-9.4\%) in case of general adsorptive media. However, interestingly, among various biochars, peanut shell-derived biochar (PSB) exhibited the best performance, showing the highest phosphate removal rate, $61.3 \%\left(3.8 \mathrm{mg} \mathrm{P_{4 }} \mathrm{P}\right.$ g $\mathrm{PSB}^{-1}$ ). We attribute this high value to the proper structural properties of PSB, such as BET-specific surface area of $348.96 \mathrm{~m}^{2} \mathrm{~g}^{-1}$ and mineral/phosphorus ratio $(\mathrm{Mg} /$ $\mathrm{P}=3.46$ and $\mathrm{Ca} / \mathrm{P}=47.6$ ). Adsorption equilibrium and kinetics of phosphate at different temperature $(10,20$, and $30{ }^{\circ} \mathrm{C}$ ) were well explained in the whole experimental region by Langmuir isotherm and pseudo-second-order kinetic models, respectively. The maximum adsorption capacity of PSB was $6.79 \mathrm{mg} \mathrm{g}^{-1}$ for phosphate at $30{ }^{\circ} \mathrm{C}$. These findings suggest that PSB has great potential as an
\end{abstract}

Kyung-Won Jung and Min-Jin Hwang have contributed equally to this work.

K.-W. Jung ( $\varangle)$ · M.-J. Hwang · K.-H. Ahn

Center for Water Resources Cycle Research, Korea Institute of Science and Technology, Hwarangno 14-gil 5, Seonbuk-gu, Seoul 136-791, Republic of Korea

e-mail: kw512@kist.re.kr

Y.-S. Ok

Department of Biological Environment, Korea Biochar Research Center, Kangwon National University, Chuncheon 200-701, Republic of Korea alternative and renewable adsorptive media for phosphate removal.

Keywords Phosphate removal - Biochar - Black carbon · Charcoal $\cdot$ Peanut shells $\cdot$ Mineral/phosphorus ratio

\section{Introduction}

It is well known that eutrophication is one of the critical environmental problems around the world today; this process is responsible for degradation of the quality of water ecosystems, global loss of biodiversity, and negative impact on the economy. These negative effects are due to the response in water to the over enrichment of point and nonpoint nutrient (nitrogen and phosphorus) loading from natural and manmade sources (urban and agricultural runoff, animal farming) (Mainstone and Parr 2002; Smith 2003). According to one report, a nitrogen/phosphorus ratio above eight and soluble reactive phosphorus concentration below $0.3 \mathrm{mg} \mathrm{L}^{-1}$ means that phosphorus is likely to be a limiting factor for part of the growing season (Mainstone et al. 1995). The average nitrogen/phosphorus ratio and phosphorus concentration of the water ecosystem in the Republic of Korea are 19.7-92.4 and $0.12 \mathrm{mg} \mathrm{L}^{-1}$, respectively (Kim et al. 2007). This means that controlling the phosphorus concentration is a crucial solution for preventing eutrophication.

Up to now, even though conventional wastewater treatment systems have been used to remove phosphate, these systems have not yet sufficiently solved the problem of eutrophication in the water ecosystem. Especially, conventional chemical precipitation using $\mathrm{Ca}, \mathrm{Al}$, and $\mathrm{Fe}$ leaded to economic burden and generation of secondary pollutants (Clark et al. 1997). Thus, the effective control 
of phosphate has been attracting a great deal of attention in the last two decades. For phosphate removal, a large number of studies have used adsorptive media such as natural products, byproducts, and man-made products (Vohla et al. 2011). Most of the adsorptive media used in these studies have had a high content of $\mathrm{Ca}, \mathrm{Al}$, and/or $\mathrm{Fe}$, which are elements with strong affinity for phosphorus binding (Westholm 2006). In addition, recently, biochar derived from agricultural residue has been employed as an alternative adsorptive media (Ahmad et al. 2014; Mohan et al. 2014). Although only a few studies have investigated the ability of biochar to remove nutrients from aqueous solution, the application of biochar derived from renewable biomass is a more suitable strategy, from environmental and economic points of view, to remove phosphate and to recycle waste (Roberts et al. 2010). In this sense, up to date, various agricultural residues and other waste have been proposed as good sources for biochar production (Cao and Harris 2010; Yand and Sheng 2003; Yao et al. 2011a; Yuan et al. 2011). However, the capacity of phosphate removal highly depends on their properties of raw material and biochar; therefore, a study of the potential for phosphate removal should be required before use.

Peanuts are a widely planted legume commodity crop worldwide; approximately 34.43 million tons of peanuts were produced in 2009. Peanuts are widely used for food, oil, and medicine; they have many other uses, as well (Zhang et al. 2013). However, the main problem is the generation of waste biomass, namely peanut shells, which constitute about $30 \%$ of peanut production (Wu et al. 2013). Most peanut shells are discarded as solid waste or are burned off in stacks, resulting in lost resources and environmental pollution; thus, there is a need to convert these shells to useful and valuable products (Ahmad et al. 2012). Therefore, if biochar derived from peanut shells can be used to remove phosphate, such a material can play a dual role in reasonable solutions to both environmental and economic issues because biochar can act as an adsorbent, as a land application for carbon sequestration, and as a valuable nutrient supplier for crops. In light of this situation, therefore, the objective of this study was to examine the feasibility of biochar derived from peanut shell for phosphate removal. As a preliminary test, five different types of biochar, oak wood, bamboo waste, maize residue, soybean stover, and peanut shells, were selected. We found that peanut shell-derived biochar (PSB) possessed the highest phosphate removal potential. In addition to monitoring the physical, chemical, and microstructural properties of biochar, we also evaluated the adsorption equilibrium and kinetic of phosphate of PSB.

\section{Materials and methods}

Preparation of adsorptive media

Biochar derived from oak and bamboo woods was supplied by the Gangwon Chamsoot Company in the Republic of Korea and by Kyushu University in Japan, respectively. Maize residue, soybean stover, and peanut shells were converted into biochar using a muffle furnace (MF 21 GS, Jeio Tech, Republic of Korea) in the absence of air. A pyrolysis temperature of $700{ }^{\circ} \mathrm{C}$ was maintained for $3 \mathrm{~h}$ (450 ${ }^{\circ} \mathrm{C}$ was used for maize residue); detailed information on the procedures of biomass pyrolysis has been described in previous research (Ahmad et al. 2012, 2013).

Phosphate adsorption test

As preliminary experiment, the comparison study of various adsorptive media on the potential of phosphate removal and desorption capacity was conducted. The phosphate concentration and adsorbent dose were fixed at $5.0 \mathrm{mg} \mathrm{L}^{-1}$ using $\mathrm{KH}_{2} \mathrm{PO}_{4}$ and $1.0 \mathrm{~g} \mathrm{~L}^{-1}$. The $\mathrm{pH}$ was adjusted at $7.0 \pm 0.1$ with $0.1 \mathrm{M}$ of $\mathrm{NaOH}$ and $\mathrm{HCl}$. Subsequently, in order to evaluate desorption capacity of phosphate from various biochars, five biochars were mixed with only DI water, and then released phosphate concentrations were monitored. The mixture of both tests was shaken for $48 \mathrm{~h}$ at $200 \mathrm{rpm}$ in an orbit shaker under temperature of $20^{\circ} \mathrm{C}$ (WIS-20R, WiseCube ${ }^{\circledR}$, Republic of Korea). Batch tests were carried out in triplicate, and average values were determined.

The adsorption isotherms were determined using batch experiments under same $\mathrm{pH}$ condition with preliminary test. The initial phosphate concentration varied from 1 to $50 \mathrm{mg} \mathrm{L}^{-1}$. The adsorption analysis was conducted by contacting $100 \mathrm{mg}$ of the prepared biochar with a $50 \mathrm{~mL}$ solution of various phosphate concentrations at different temperatures. The mixture was homogeneously shaken for $48 \mathrm{~h}$ at $200 \mathrm{rpm}$ in an orbit shaker, which is sufficient for reaching equilibrium. Furthermore, the dynamic adsorption analysis was also carried out in $10 \mathrm{mg} \mathrm{L}^{-1}$ of initial concentration at various temperatures $\left(10-30^{\circ} \mathrm{C}\right)$. All experiments were conducted with $1.5 \mathrm{~g}$ of prepared biochar in $1.0 \mathrm{~L}$ of phosphate solution at $\mathrm{pH} 7.0 \pm 0.1$. During the experiments, aliquots of the sample were taken periodically from the reaction vessel for characterization. The samples were immediately filtered through a $0.45-\mu \mathrm{m}$ membrane filter, residual phosphate concentrations in filtrates were triplicate determined, and average values are reported. The phosphate removal ratio and adsorbed amount were also calculated using the following relationships: 
Removal ratio $(\%)=\frac{C_{i}-C_{t}}{C_{i}} \times 100$

Amount adsorbed $\left(q_{t}\right)=\frac{V}{M}\left(C_{i}-C_{t}\right)$

where $C_{i}$ and $C_{t}$ are the corresponding concentration (mg L $\mathrm{L}^{-1}$ ) of phosphate at the initial time and the given time, respectively, $q_{t}$ is the adsorbed amounts of phosphate per unit weight of adsorbent $\left(\mathrm{mg} \mathrm{g}^{-1}\right)$ at given time, $M(\mathrm{~g})$ is the mass of adsorbent, and $V$ is the volume of phosphate solution (L).

\section{Analytical method}

Chemical analysis of the various types of biochar was performed using a ZSX Primus-II X-ray Fluorescence device (XRF-Rigaku Co., Japan). Zeta potential was measured using a zeta potential analyzer (Zetasizer Nano ZS, Malvern Instrument Ltd., UK). The porous textured properties (i.e., BET-specific surface area, total pore volume, and average pore diameter) of the samples were characterized by nitrogen adsorption/desorption studies at $77 \mathrm{~K}$ using a nanoporosity system (NP-XQ, Mirae Scientific Instruments, Republic of Korea). Oxygen/carbon ratios of raw biomass were analyzed using energy-dispersive X-ray spectroscopy (EDS, S-4200, Hitachi Co., Japan). The concentration of phosphate of the liquid phase (filtrated through a $0.45 \mu \mathrm{m}$ pore size syringe filter) was analyzed using an ion chromatographer (DX-120, Dionex, USA). The mineral content of various biochars was analyzed using X-ray diffraction (XRD, D8 Advance Sol-X, Bruker Co., USA).

\section{Results and discussion}

Textural properties of biochar derived from various biomass

The various biochars derived from biomass were characterized using nitrogen adsorption-desorption analyses to determine the textural properties. The nitrogen adsorption isotherms of the prepared biochars are shown in Fig. 1a. Three kinds of the biochar derived from soybean stover, bamboo wood, and peanut shells show type IV isotherms, which suggest the presence of mesoporous pores. The oak wood and the maize residue were typical type I and type II isotherms according to the International Union of Pure and Applied Chemistry (IUPAC) classification, which are indicative of microporous and non-porous (or macroporous) materials, respectively (Hwang et al. 2012). The textural properties such as surface area, average pore size, and pore volume were estimated from well-known calculation methods such as the Brunauer-Emmett-Teller (BET), the BarrettJoyner-Halenda (BJH), and the Horvath-Kawazoe (HK). Figure $1 \mathrm{~b}$ shows the pore size distributions of the mesoporous biochars estimated by the BJH method from desorption branches. The overall textural properties of the prepared biochars are summarized in Table 1. A much higher surface area and a narrower pore size distribution were obtained for PSB, when compared with biochar from other biomass sources. In general, the volatile material as oxygen could be removed at high carbonization temperature resulting in increased pore structures including the pore volume, pore area, and specific surface area (Ahmad et al. 2012). Especially, the highest oxygen/ carbon ratio of low material was investigated in law peanut shell as shown in Table 1. According to this observation, the higher specific surface area was obtained at higher oxygen/carbon ratios. The specific surface area and pore volume of the PSB were $328.96 \mathrm{~m}^{2} \mathrm{~g}^{-1}$ and $0.43 \mathrm{~cm}^{3} \mathrm{~g}^{-1}$, respectively. These structural analysis results could account for the higher uptake of phosphate due to a relatively high surface area and well-developed mesoporous pores. Based on physical properties of various biochars, a feasibility test for phosphate removal was conducted, and the detailed experimental results are described in the next section.
Fig. 1 Textural properties of various biochars: a nitrogen adsorption-desorption isotherms at $77 \mathrm{~K}$ (color adsorption; blank desorption) and $\mathbf{b}$ the Barrett-JoynerHalenda (BJH) pore size distributions of the prepared biochars. $O W B$ oak wood, $S S B$ soybean, $B W B$ bamboo wood, $M R B$ maize residue, $P S B$ peanut shell
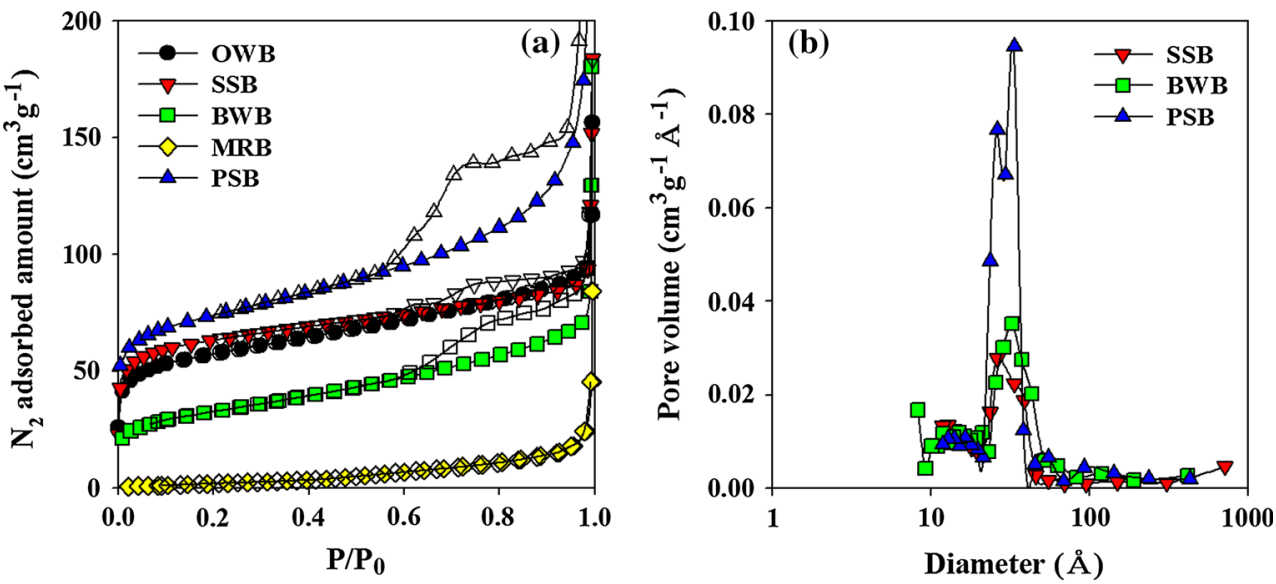
Table 1 Physical properties of the various biochars derived from biomass

\begin{tabular}{|c|c|c|c|c|c|c|}
\hline \multirow[t]{2}{*}{ Materials } & \multirow[t]{2}{*}{ BET surface area $\left(\mathrm{m}^{2} \mathrm{~g}^{-1}\right)$} & \multicolumn{2}{|c|}{ Pore diameter $(\mathrm{nm})$} & \multicolumn{2}{|c|}{ Pore volume $\left(\mathrm{cm}^{3} \mathrm{~g}^{-1}\right)$} & \multirow{2}{*}{$\begin{array}{l}{ }^{\mathrm{a}} \mathrm{O} / \mathrm{C} \text { ratio } \\
(\%)\end{array}$} \\
\hline & & Micro & Meso & Micro & Meso & \\
\hline Oak wood (OWB) & 185.54 & 1.67 & 3.53 & 0.15 & 0.06 & 8.43 \\
\hline Soybean stover (SSB) & 247.09 & 1.03 & 4.14 & 0.11 & 0.18 & 9.08 \\
\hline Bamboo wood (BWB) & 110.52 & 1.31 & 4.05 & 0.04 & 0.13 & 9.38 \\
\hline Maize residue (MRB) & 10.79 & 1.81 & 4.48 & 0.04 & 0.01 & 5.66 \\
\hline Peanut shel (PSB)l & 328.96 & 1.25 & 5.38 & 0.04 & 0.39 & 38.59 \\
\hline
\end{tabular}

${ }^{a}$ EDS analysis for oxygen/carbon ratio of raw biomass

Fig. 2 Comparison study of potential on a phosphate removal rate capacity of various biochars and $\mathbf{b}$ desorption capacity of phosphate from various biochars (mixing with DI water after 48 h. $O W B$ oak wood, $S S B$ soybean, $B W B$ bamboo wood, $M R B$ maize residue, $P S B$ peanut shell

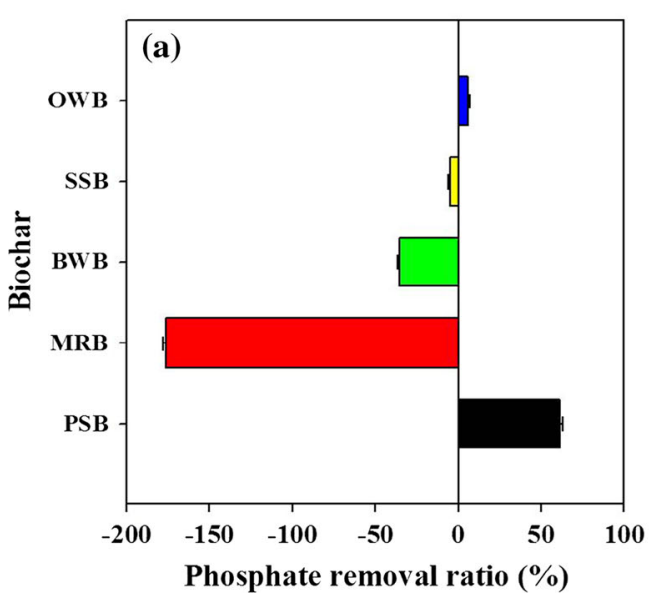

Feasibility test of various biochars for phosphate removal

Figure $2 \mathrm{a}$ shows the phosphate removal rate after $48 \mathrm{~h}$ using various biochars. It can be clearly seen that among the various biochars, only the two biochars derived from oak wood and peanut shells have the positive capability of phosphate removal. The highest phosphate removal rate, $61.3 \%$, was obtained using the PSB, while the general adsorptive media showed very limited phosphate removal, in a range of 2.0 to $9.4 \%$. In addition, interestingly, unlike biochars derived from oak wood and peanut shells, the concentration of phosphate actually increased after $48 \mathrm{~h}$ of reaction time with other types of biochar, especially maize residue-derived biochar $\left(13.8 \mathrm{mg} \mathrm{L}^{-1}\right)$. It is well known that phosphorus desorption capability is significantly related to the divalent cation bridging and nano-sized periclase (MgO) of biochar (Hale et al. 2013; Mukherjee and Zimmerman 2013). As can be seen in Table 2, Mg and Ca were the main components in all biochars; in particular, PSB had the highest $\mathrm{Ca}$ content. The calculated $\mathrm{Mg} / \mathrm{P}$ and $\mathrm{Ca} / \mathrm{P}$ ratios were determined from XRF results for the prepared biochars, with data given in Table 3 . All of these ratios, for soybean stover, bamboo wood, and maize residue, were much lower than the same ratios for oak wood and peanut shells, indicating that the extraction of phosphate from biochar into aqueous solution might occur due to the low holding capability (low ionic strength) of the phosphorus content in biochar, which is caused by the low $\mathrm{Mg}$ and $\mathrm{Ca}$ content in biochar. These results coincide with the extracted phosphate concentrations after mixing samples together with only DI water and biochar for $48 \mathrm{~h}$ (tests were done three times), as shown in Fig. 2b, in which the concentrations of phosphate were $(0.7 \pm 1.1) \mathrm{mg} \mathrm{L}^{-1}$, $(1.6 \pm 0.5) \mathrm{mg} \mathrm{L}^{-1}$, and $(9.5 \pm 0.8) \mathrm{mg} \mathrm{L}^{-1}$ in soybean stover, bamboo wood, and maize residue, respectively. However, phosphate was not detected in the samples with oak wood and peanut shells. Normally, the surfaces of charcoals are negatively charged, which makes them unlikely to sorb negatively charged ions such as phosphate (Lee et al. 2010; Eberhardt et al. 2006). The measured zeta potentials of the various biochars were negative, as shown in Table 3, confirming that the biochars employed here were negatively charged under circumneutral conditions. However, among the samples, PSB had the highest zeta potential $(-16.0 \mathrm{mV})$, indicating that this type of biochar might be more suitable for phosphate adsorption. Measurements of the $\mathrm{pH}$ of each type of biochar showed values that were alkaline, at approximately $\mathrm{pH} 10.0$, which values are similar to the values reported for other biochars 
Table 2 Chemical property (XRF) of biochars

${ }^{\mathrm{a}}$ Unit $=$ mass $\%$

Table 3 Characteristics of biochar samples water) ratio

\begin{tabular}{lcclcc}
\hline Components $^{\mathrm{a}}$ & Oak wood & Soybean stover & Bamboo wood & Maize residue & Peanut shell \\
\hline $\mathrm{C}$ & 98.00 & 92.80 & 96.00 & 92.20 & 89.00 \\
$\mathrm{Na}$ & - & 0.03 & - & - & 0.12 \\
$\mathrm{Mg}$ & 0.07 & 0.64 & 0.13 & 0.29 & 0.51 \\
$\mathrm{Al}$ & 0.01 & 0.15 & - & 0.11 & 1.39 \\
$\mathrm{Si}$ & 0.02 & 0.37 & 0.14 & 1.83 & 1.15 \\
$\mathrm{P}$ & 0.02 & 0.46 & 0.24 & 0.56 & 0.15 \\
$\mathrm{~S}$ & 0.02 & 0.11 & 0.11 & 0.06 & 0.14 \\
$\mathrm{~K}$ & 0.66 & 2.97 & 2.98 & 4.07 & 0.11 \\
$\mathrm{Ca}$ & 1.17 & 2.25 & 0.13 & 0.73 & 7.00 \\
$\mathrm{Fe}$ & 0.02 & 0.13 & 0.03 & 0.05 & 0.25 \\
\hline
\end{tabular}

\begin{tabular}{lccccc}
\hline Parameters & Oak wood & Soybean stover & Bamboo wood & Maize residue & Peanut shell \\
\hline Zeta potential $(\mathrm{mV})$ & -26.50 & -40.30 & -43.10 & -45.10 & -16.00 \\
$\mathrm{pH}^{\mathrm{a}}$ & 10.51 & 10.60 & 10.41 & 10.42 & 10.01 \\
$\mathrm{Mg} / \mathrm{P}$ ratio & 2.82 & 1.39 & 0.53 & 0.51 & 3.46 \\
$\mathrm{Ca} / \mathrm{P}$ ratio & 50.20 & 4.86 & 0.53 & 1.30 & 47.60 \\
\hline
\end{tabular}

produced at high temperatures; the high $\mathrm{pH}$ of the biochar samples suggests their potential for use as upgrader to reduce soil acidity (Yao et al. 2011a; Cao and Harris 2010; Lucchini et al. 2014).

\section{Adsorption equilibrium of phosphate on PSB}

In order to further investigate the adsorption properties of $\mathrm{PSB}$, the adsorption equilibrium isotherms of phosphate were measured at three different temperatures $(10,20$, and $30{ }^{\circ} \mathrm{C}$ ), and the results are shown in Fig. 3a. The maximum adsorption capacities of PSB were 3.67, 5.50, and $6.79 \mathrm{mg} \mathrm{g}^{-1}$ at 10,20 , and $30^{\circ} \mathrm{C}$, respectively. Furthermore, PSB has a quite high adsorption capability for phosphate compared to reported other biomaterials, e.g., $4.8 \mathrm{mg} \mathrm{g}^{-1}$ for okara (Nguyen et al. 2013), $4.3 \mathrm{mg} \mathrm{g}^{-1}$ for aspen wood fiber (Eberhardt et al. 2006), $2.3 \mathrm{mg} \mathrm{g}^{-1}$ for juniper fiber (Han et al. 2005), and $4.4 \mathrm{mg} \mathrm{g}^{-1}$ for palm fiber (Riahi et al. 2009). The adsorption capacities for PSB increased with an increasing temperature, suggesting that the system is an endothermic and chemical process. In addition, with an increase in the reaction temperature, the interaction forces between the adsorbate and the aqueous solution become weaker than those between the solute and adsorbent. As a consequence, the adsorbate might be easily adsorbing on the adsorbent (Vasudevan and Lakshmi 2012). This result was identical to those of previous studies of phosphate adsorption in aqueous solution on iron hydroxide-eggshell waste (Mezenner and Bensmaili 2009), $\mathrm{ZnCl}_{2}$ activated coir pith carbon (Namasivayam and Sangeetha 2004), aluminum hydroxide (Guan et al. 2007), and red mud (Huang et al. 2008). Additionally, the adsorbed amounts of phosphate were analyzed with two commonly used isotherms, Langmuir and Freundlich models given as follows (Yao et al. 2011a):Langmuir;

$q_{\mathrm{e}}=\frac{q_{\mathrm{m}} K_{L} C_{\mathrm{e}}}{1+K_{L} C_{\mathrm{e}}}$

Freundlich;

$q_{\mathrm{e}}=K_{F} C_{\mathrm{e}}^{1 / n}$

where $q_{\mathrm{e}}$ is the adsorbed amounts of phosphate per unit weight of adsorbent $\left(\mathrm{mg} \mathrm{g}^{-1}\right)$ at an equilibrium concentration of adsorbate in bulk solution $\left(\mathrm{C}_{\mathrm{e}}, \mathrm{mg} \mathrm{L}^{-1}\right) . K_{L}$ and $K_{F}$ are the Langmuir and Freundlich constants, respectively. $q_{\mathrm{m}}$ is maximum adsorption capacity, and $1 / n$ is the heterogeneity factor. The parameters for both the isotherms were obtained and are listed in Table 4. According to the regression coefficient $\left(R^{2}\right)$ values determined from those models, the results from the Langmuir isotherm model (exceeding 0.98) more precisely agreed with the experimental data than the Freundlich isotherm model at different temperatures. As can be seen from Langmuir isotherm, the increase in reaction temperature leads to an increased maximum adsorption capacity from $4.243 \mathrm{mg} \mathrm{g}^{-1}$ at $10{ }^{\circ} \mathrm{C}$ to $7.567 \mathrm{mg} \mathrm{g}^{-1}$ at $30{ }^{\circ} \mathrm{C}$. Moreover, an increase in Langmuir constant (adsorption driving force) with increasing reaction temperature indicated that the main mechanism of PSB was endothermic and chemical adsorption as before-mentioned. The implication of the Langmuir isotherm suggests that the adsorption of phosphate onto the PSB surface was probably energetically homogeneous. Subsequently, the effect of $\mathrm{pH}$ on the phosphate adsorption capacities onto PSB was examined in 
Fig. 3 Adsorption capacity of phosphate: a adsorption equilibrium isotherms of at $\mathrm{pH} 7$ and $\mathbf{b}$ adsorption capacities at various solution $\mathrm{pH}$ on $\mathrm{PSB}$
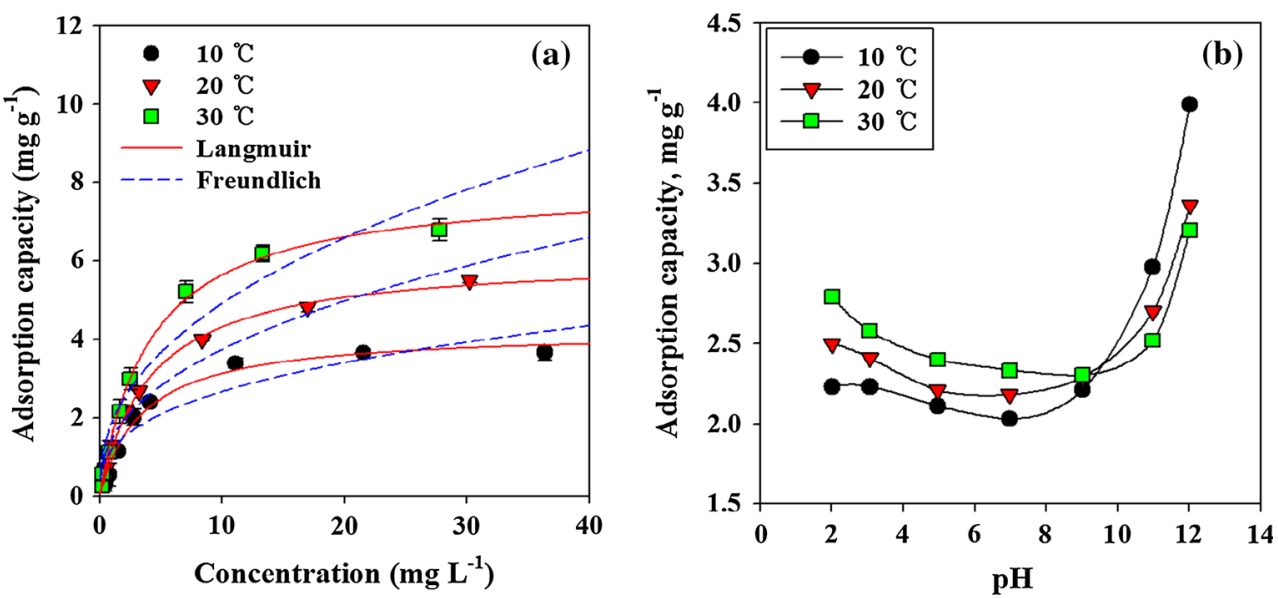

Table 4 Langmuir and Freundlich isotherm parameters for phosphate adsorption on peanut shell biochar

a Squared correlation coefficient

\begin{tabular}{llllllll}
\hline $\begin{array}{l}\text { Temperature } \\
\left({ }^{\circ} \mathrm{C}\right)\end{array}$ & \multicolumn{2}{l}{ Langmuir model } & & \multicolumn{2}{l}{ Freundlich model } \\
\cline { 2 - 3 } & $\mathrm{Q}_{\mathrm{m}}\left(\mathrm{mg} \mathrm{g}^{-1}\right)$ & $K_{L}\left(\mathrm{~L} \mathrm{mg}^{-1}\right)$ & $R^{2 \mathrm{a}}$ & & $K_{F}\left(\mathrm{mg} \mathrm{g}^{-1}\right)$ & $\mathrm{N}$ & $R^{2 \mathrm{a}}$ \\
\hline 10 & 4.243 & 0.251 & 0.985 & 1.193 & 0.351 & 0.872 \\
20 & 6.011 & 0.276 & 0.998 & 1.466 & 0.408 & 0.957 \\
30 & 7.567 & 0.312 & 0.998 & 1.863 & 0.422 & 0.935 \\
\hline
\end{tabular}

a series of experiments that used a $10 \mathrm{mg} \mathrm{L}^{-1}$ initial phosphate concentration while maintaining the $\mathrm{pH}$ at different values between 2.0 and 12.0 with various temperature conditions. The $\mathrm{pH}$ dependence of phosphate adsorption is presented in Fig. 3b. The results show that the adsorption capacity of phosphate decreases gradually with an increasing $\mathrm{pH}$ at between 2.0 and 7.0 and then tends to approach a minimum adsorption capacity, after which it sharply increases with further increases in $\mathrm{pH}$ until $\mathrm{pH}$ 12.0. In general, when the $\mathrm{pH}$ of the solution increases, there is a lower phosphate adsorption capacity resulting from repulsive forces because a higher $\mathrm{pH}$ causes the adsorbent surface to carry more negative charges and thus significantly repulses the negatively charged solute in solution (Kim et al. 2002; Singh et al. 2005; Yang et al. 2006). However, the maximum adsorption capacity of PSB for phosphate was obtained at $\mathrm{pH}$ 12.0, as confirmed in Fig. 3b. It is well known that calcite $\left(\mathrm{CaCO}_{3}\right)$ can act as phosphate adsorbent, thereby influencing the phosphate sorption or desorption fluxes (Sø et al. 2011; Suzuki et al. 1986). With respect to $\mathrm{pH}$ condition, the phosphate adsorption efficiency could be increased with increasing $\mathrm{pH}$ condition due to inverse correlation between $\mathrm{Ca}^{2+}$ and $\mathrm{CO}_{3}{ }^{2-}$ (increase and decrease in the activities of $\mathrm{Ca}^{2+}$ and $\mathrm{CO}_{3}{ }^{2-}$, respectively). As shown in Fig. 4, the mineralogical analysis was carried out using XRD in order to investigate the crystal structure of various biochars. In the XRD diagrams, except bamboo wood-derived biochar (C) and maize residue-derived biochar $(\mathrm{d})$, crystallized section of others was characterized as calcite. In particular, PSB was characterized as calcite with the highest peak intensity, leading to the highest phosphate adsorption performance. Therefore, in this study, the $\mathrm{pH}$ dependency of phosphate removal might be related to the polyprotic nature of phosphate and also correlated with the dissolution of $\mathrm{Ca}^{2+}$ ions. PSB contains many minerals (especially the $7 \%$ of calcium mentioned above) as shown in Table 2. These constituent species can undergo various hydrolysis and complex formation reactions (Karageorgiou et al. 2007).

\section{Adsorption kinetics of phosphate on PSB}

Kinetic studies on the adsorption process is usually conducted to establish the reaction time that is required to achieve the maximum adsorbing capacity of the adsorbate on the adsorbent. To identify the adsorption kinetic, the mass transfer behavior of the phosphate on PSB was measured in terms of contact time at various reaction temperatures. As clearly shown in Fig. 5a, the adsorption of phosphate occurred in three stages at all reaction temperatures. The adsorption rate was rapid in the initial stage of the reaction due to a high number of fresh binding sites available for adsorption in the first stage (Ghaedi et al. 2011), reaching $2.4 \mathrm{mg} \mathrm{g}^{-1}$ for the phosphate adsorption capacity, which is above $80 \%$ of the quantity of maximum adsorption capacity within $4 \mathrm{~h}$ at $30^{\circ} \mathrm{C}$. After the first stage, the rate progressively decreased with contact time until it achieved equilibrium. According to Fig. 5a, the 

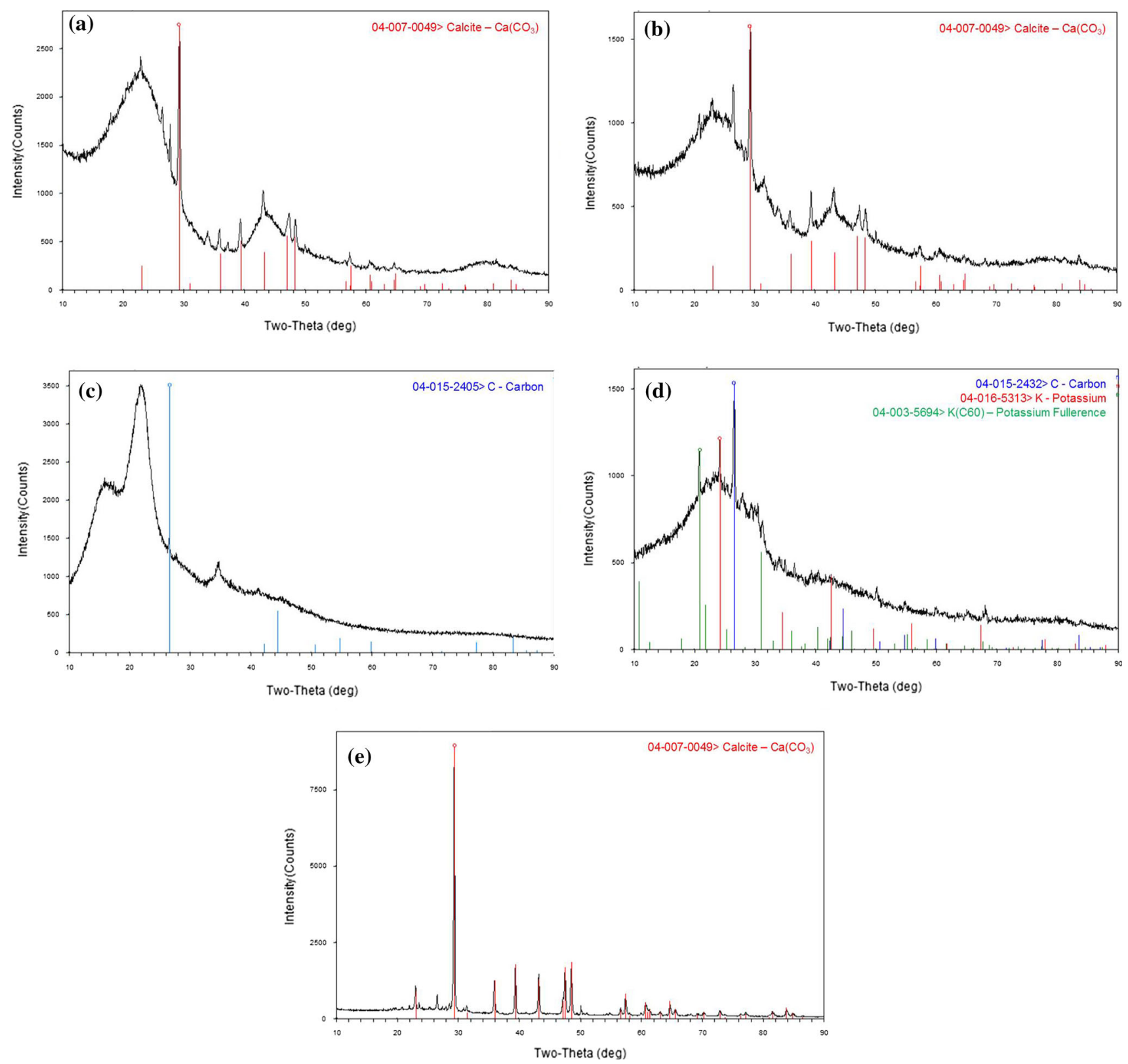

Fig. 4 XRD patterns of various biochars: a oak wood, $\mathbf{b}$ soybean stover, $\mathbf{c}$ bamboo wood, $\mathbf{d}$ maize residue, $\mathbf{e}$ peanut shell

phosphate adsorption in the PSB process could require more than $20 \mathrm{~h}$ to reach equilibrium.

Although many mathematical models, including the surface diffusion model, pore diffusion model, and combined diffusion model, have been given a strict interpretation of the mass transient of the adsorbate inside adsorbent, the mathematical complexity of the models makes them inconvenient for practical use (Ho and Mckay 1998). The adsorption kinetics were analyzed based on two different kinetic models: the pseudo-first-order and pseudosecond-order models (Yao et al. 2011b).
Pseudo-first order;

$\frac{d q_{t}}{\mathrm{~d} t}=K_{p 1}\left(q_{e}-q_{t}\right)$

Pseudo-second order;

$\frac{d q_{t}}{\mathrm{~d} t}=K_{p 2}\left(q_{e}-q_{t}\right)^{2}$

where $K_{p 1}$ and $K_{p 2}$ are rate constants for the pseudo-firstorder model $\left(\mathrm{h}^{-1}\right)$ and pseudo-second-order model ( $\mathrm{g} \mathrm{mg}^{-1} \mathrm{~h}^{-1}$ ), respectively. $q_{t}$ is the adsorbed amount at a given time, and $q_{e}$ is the adsorbed amounts at equilibrium. 
Fig. 5 PSB at various temperatures with a $10 \mathrm{mg} \mathrm{L}^{-1}$ of phosphate aqueous solution: a the pseudo-kinetic model and b Weber-Morris model
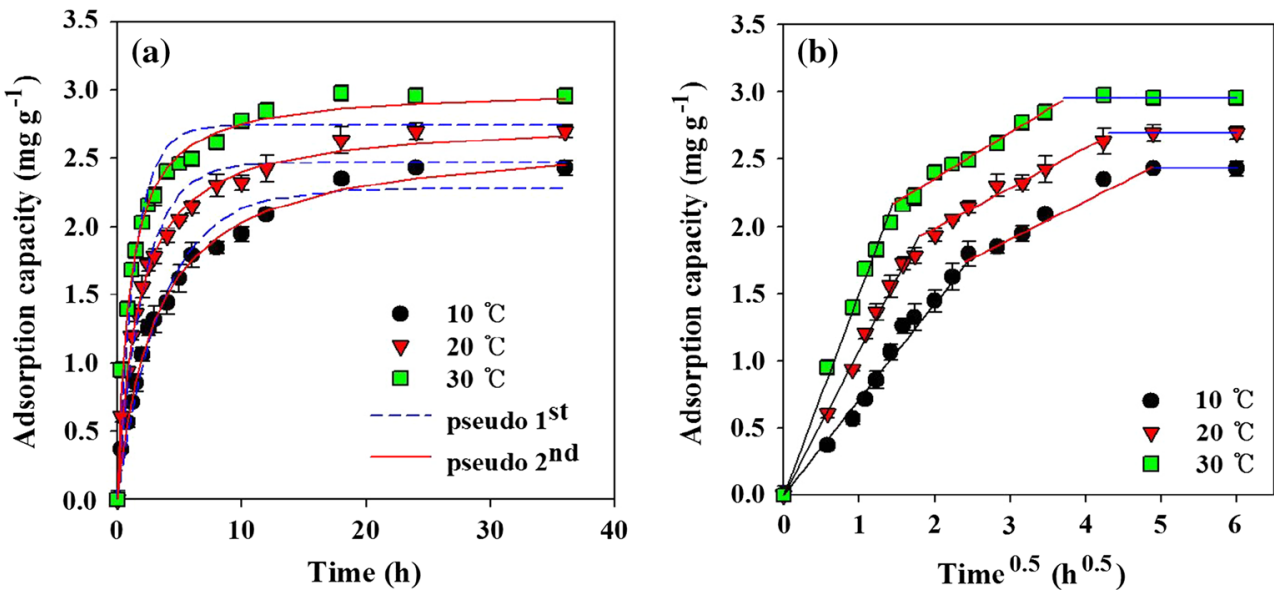

Table 5 Kinetic parameters of pseudo- and Weber-Morris models

${ }^{a}$ Squared correlation coefficient

\begin{tabular}{|c|c|c|c|c|c|c|c|c|c|}
\hline \multicolumn{2}{|c|}{ Experimental results } & \multicolumn{3}{|c|}{ Pseudo-first order } & \multicolumn{3}{|c|}{ Pseudo-second order } & \multicolumn{2}{|c|}{ Intraparticle diffusion } \\
\hline $\begin{array}{l}\text { Temp. } \\
{ }^{\circ} \mathrm{C}\end{array}$ & $\begin{array}{l}\mathrm{Q}_{\mathrm{e}}(\operatorname{Exp}) \\
\mathrm{mg} \mathrm{g}^{-1}\end{array}$ & $\begin{array}{l}\mathrm{Q}_{\mathrm{e}}(\text { Pre }) \\
\mathrm{mg} \mathrm{g}^{-1}\end{array}$ & $\begin{array}{l}K_{p 1} \\
\mathrm{~h}^{-1}\end{array}$ & $\begin{array}{l}R^{2 \mathrm{a}} \\
-\end{array}$ & $\begin{array}{l}\mathrm{Q}_{\mathrm{e}} \text { (Pre) } \\
\mathrm{mg} \mathrm{g}^{-1}\end{array}$ & $\begin{array}{l}K_{p 2} \\
\mathrm{~g} \mathrm{mg}^{-1} \mathrm{~h}^{-1}\end{array}$ & $\begin{array}{l}R^{2 \mathrm{a}} \\
-\end{array}$ & $\begin{array}{l}\mathrm{K}_{\mathrm{i} 2} \\
\mathrm{mg} \mathrm{g}^{-1} \mathrm{~h}^{-0.5}\end{array}$ & $\begin{array}{l}R^{2 \mathrm{a}} \\
-\end{array}$ \\
\hline & 2.449 & 2.277 & 0.276 & 0.974 & 2.661 & 0.121 & 0.995 & 0.284 & 0.975 \\
\hline & 2.665 & 2.469 & 0.475 & 0.960 & 2.784 & 0.223 & 0.995 & 0.300 & 0.975 \\
\hline & 2.936 & 2.742 & 0.718 & 0.949 & 3.015 & 0.345 & 0.993 & 0.342 & 0.980 \\
\hline
\end{tabular}

In this study, we used a MATLAB program to directly evaluate the kinetic parameters by an optimization method. The evaluated parameters are listed together with the regression coefficients in Table 5. Taking into account the regression coefficient $\left(R^{2}\right)$ values, the adsorption kinetic experimental results at three different temperatures can be better explained in terms of the pseudo-second-order model. Based on the pseudo-second-order model, the calculated $q_{e}$ (predicted) values were close to the experimental $q_{e}$ values and also the values of $R^{2}$ were quite near 1.0 , as shown in Table 5. The kinetic rate constant was in the range of 0.121 to $0.345 \mathrm{~g} \mathrm{mg}^{-1} \mathrm{~h}^{-1}$ and increased with an increasing reaction temperature. The pseudo-second-order rate expression was used to describe chemisorption involving valency forces through the sharing or exchange of electrons between the adsorbent and adsorbate as covalent forces (Ho 2006).

However, the pseudo-kinetic models could not be satisfactorily explained for the diffusion mechanism of phosphate on PSB. The possibility of intraparticle diffusion resistance affecting adsorption was determined using a Weber-Morris model. The equation is given as (Weber and Morris 1963):Weber-Morris;

$q_{t}=K_{i 2} t^{0.5}$

where $K_{i 2}$ is the intraparticle diffusion rate constant (mg. $\mathrm{g}^{-1} \mathrm{~h}^{-0.5}$ ) that can be obtained from the slop in the plot of $q_{t}$ versus $t^{0.5}$ as shown in Fig. 5b. There are two different kinetic regions in the phosphate adsorption process. The first region could be attributed to either the boundary layer diffusion effect or the mass transfer effects on the external surface. The second straight portion representing the internal pore includes mesopores and micropores of the prepared PSB (Tutem et al. 1998). The intraparticle diffusion rate constant $K_{i 2}$ was obtained from the second slope in Fig. 5b and is listed in Table 5. These values were $0.284-0.342 \mathrm{mg} \cdot \mathrm{g}^{-1} \mathrm{~h}^{-0.5}$. These results demonstrated that the overall adsorption process might be controlled by the solution temperature, which highly affected the external mass transfer and intraparticle diffusion rate of the phosphate molecules.

\section{Conclusion}

In this study, we evaluated five types of biochar for phosphate removal in aqueous solution. Among the various adsorptive media, PSB exhibited the best phosphate removal efficiency due to suitable chemical and physical properties, compared to the other types of biochar and adsorptive media. Even though these findings suggest that PSB has great potential as an alternative and renewable adsorptive media for phosphate removal, further study for continuous operation in column tests or for application with constructed wetland as media might be necessary to successfully apply these media in the field. 
Acknowledgments This work was supported by grants from the Korea Research Council of Fundamental Science and Technology and the KIST Institutional Program.

\section{References}

Ahmad M, Lee SS, Dou X, Mohan D, Sung JW, Yang JE, Ok YS (2012) Effects of pyrolysis temperature on soybean stover- and peanut shell-derived biochar properties and TCE adsorption in water. Bioresour Technol 118:536-544

Ahmad M, Lee SS, Oh SE, Mohan D, Moon DH, Lee YH, Ok YS (2013) Modeling adsorption kinetics of trichloroethylene onto biochars derived from soybean stover and peanut shell wastes. Environ Sci Pollut Res 20:8364-8373

Ahmad M, Rajapaksha AU, Lim JE, Zhang M, Bolan N, Mohan D, Vithanage M, Lee SS, Ok YS (2014) Biochar as a sorbent for contaminant management in soil and water: a review. Chemosphere 99:19-33

Cao XD, Harris W (2010) Properties of dairy-manure-derived biochar effectively sorbs lead and atrazine. Environ Sci Technol 43:3285-3291

Clark T, Stephenson T, Pearce PA (1997) Phosphorus removal by chemical precipitation in a biological aerated filter. Water Res 31:2557-2563

Eberhardt TL, Min SH, Han JS (2006) Phosphate removal by refined aspen wood fiber treated with carboxymethyl cellulose and ferrous chloride. Bioresour Technol 97:2371-2376

Ghaedi M, Hassanzadeh A, Kokhdan SN (2011) Multiwalled carbon nanotubes as adsorbents for the kinetic and equilibrium study of the removal of alizarin red $\mathrm{s}$ and morin. J Chem Eng Data 56:2511-2520

Guan XH, Chen GH, Shang C (2007) Adsorption behavior of condensed phosphate on aluminum hydroxide. J Environ Sci 19:312-318

Hale SE, Alling V, Martinsen V, Mulder J, Breedveld GD, Cornelissen G (2013) The sorption and desorption of phosphate-P, ammonium-N and mitrate- $\mathrm{N}$ in cacao shell and corn cob biochars. Chemosphere 91:1612-1619

Han JS, Min SH, Kim YK (2005) Removal of phosphorous using AMD treated lignocellulosic material. For Prod J 55:48-53

Ho YS (2006) Review of second-order models for adsorption systems. J Hazard Mater 136:681-689

Ho YS, Mckay G (1998) A comparison of chemisorption kinetic models applied to pollutant removal on various sorbents. Process Saf Environ Protect 76:332-340

Huang W, Wang S, Zhu Z, Li L, Yao X, Rudolph V, Haghseresht F (2008) Phosphate removal from wastewater using red mud. J Hazard Mater 158:35-42

Hwang MJ, Shim WG, Ryu DW, Moon H (2012) Low-pressure adsorption isotherms of aromatic compounds on polyisobutylene gel measured on a quartz crystal microbalance. J Chem Eng Data 57:701-707

Karageorgiou K, Paschalis M, Anastassakis GN (2007) Removal of phosphate species from solution by adsorption onto calcite used as natural adsorbent. J Hazard Mater 139:447-452

Kim JG, Kim JH, Moon HS, Chon CM, Ahn JS (2002) Removal capacity of water plant alum sludge for phosphorus in aqueous solutions. Chem Spec Bioavailab 14:67-73

Kim BC, Sa SH, Kim MS, Lee YK, Kim JK (2007) The limiting nutrient of eutrophication in reservoirs of Korea and the suggestion of a reinforced phosphorus standard for sewage treatment effluent. Korean Soci Water Quality 23:512-517 (In Korean)

Lee JW, Kidder M, Evans BR, Paik S, Buchanan AC III, Garten CT, Brwon RC (2010) Characterization of biochars produced from cornstovers for soil amendments. Environ Sci Technol 44:7970-7974

Lucchini P, Quilliam RS, DeLuca TH, Vamerali T, Jones DL (2014) Increased bioavailability of metals in two contrasting agricultural soils treated with waste wood-derived biochar and ash. Environ Sci Pollut Res 21:3230-3240

Mainstone CP, Parr W (2002) Phosphorus in revers-ecology and management. Sci Total Environ 282-283:25-47

Mainstone CP, Ashley S, Gunby A, Parr W, Woodrow D, Turton P, McAllem Y (1995) Development and testing of general quality assessment schemes: nutrients in rivers and canals. NRA R\&D Project Record 469/11/HO. National Rivers Authority, Bristol

Mezenner NY, Bensmaili A (2009) Kinetics and thermodynamic study of phosphate adsorption on iron hydroxide-eggshell waste. Chem Eng J 147:87-96

Mohan D, Sarswat A, Ok YS, Charles U, Pittman J (2014) Organic and inorganic contaminants removal from water with biochar, a renewable, low cost and sustainable adsorbent-a critical review. Bioresour Technol 160:191-202

Mukherjee A, Zimmerman AR (2013) Organic carbon and nutrient release from a range of laboratory-produced biochars and biochar-soil mixtures. Geoderma 193-194:122-130

Namasivayam C, Sangeetha D (2004) Equilibrium and kinetic studies of adsorption of phosphate onto $\mathrm{ZnCl}_{2}$ activated coir pith carbon. J Colloid Interface Sci 280:359-365

Nguyen TAH, Ngo HH, Guo WS, Zhang J, Liang S, Tung KL (2013) Feasibility of iron loaded 'okara' for biosorption of phosphorous in aqueous solutions. Bioresour Technol 150:42-49

Riahi K, Thayer BB, Mammou AB, Ammar AB, Jaafoura MH (2009) Biosorption characteristics of phosphates from aqueous solution onto Phoenix dactylifera L. date palm fibers. J Hazard Mater 170:511-519

Roberts KG, Gloy BA, Joseph S, Scott NR, Lehmann J (2010) Life cycle assessment of biochar systems: estimating the energetic, economic, and climate change potential. Environ Sci Technol 44:827-833

Singh BP, Menchavez R, Takai C, Fuji M, Takahashi M (2005) Characterization of concentrated colloidal ceramics suspension: a new approach. J Colloid Interface Sci 300:163-168

Smith VH (2003) Eutrophication of freshwater and coastal marine ecosystems a global problem. Environ Sci Pollution Res $10: 126-139$

Sø HU, Postma D, Jakobsen R, Larsen F (2011) Sorption of phosphate onto calcite; results from batch experiments and surface complexation modeling. Ceochim Cosmochim Acta 75:2911-2923

Suzuki T, Inomata S, Sawada K (1986) Adsorption of phosphate on calcite. J Chem Soc Faraday Trans 82:1733-1743

Tutem E, Apak R, Unal C (1998) Adsorptive removal of chlorophenols from water by bituminous shale. Water Res 32:2315-2324

Vasudevan S, Lakshmi J (2012) The adsorption of phosphate by graphene from aqueous solution. RSC Adv 2:5234-5242

Vohla C, Kõiv M, Bavor HJ, Chazarenc F, Mander Ü (2011) Filter materials for phosphorus removal from wastewater in treatment wetlands-a review. Ecol Eng 37:70-89

Weber WJ, Morris JC (1963) Kinetics of adsorption on carbon from solution. J Sanit Eng Div. Am Soc Civ Eng 89:31-60

Westholm LJ (2006) Substrates for phosphorus removal-potential benefits for on-site wastewater treatment. Water Res 40:23-36

Wu M, Guo Q, Fu G (2013) Preparation and characteristics of medicinal activated carbon powders by $\mathrm{CO}_{2}$ activation of peanut shells. Powder Technol 247:188-196

Yang YN, Sheng GY (2003) Pesticide adsorptivity of aged particulate matter arising from crop residue burns. J Agric Food Chem 51:5047-5051 
Yang Y, Zhao YQ, Babatunde AO, Wang L, Ren YX, Han Y (2006) Characteristics and mechanisms of phosphate adsorption on dewatered alum sludge. Sep Purif Technol 51:193-200

Yao Y, Gao B, Inyang M, Zimmerman AR, Cao X, Pullammanappallil P, Yang L (2011a) Removal of phosphate from aqueous solution by biochar derived from naerobically digested sugar beet tailings. J Hazard Mater 190:501-507

Yao Y, Gao B, Inyang M, Zimmerman AR, Cao X, Pullammananppallil P, Yang L (2011b) Biochar derived from anaerobically digested sugar beet tailings: characterization and phosphate removal potential. Bioresour Technol 102:6273-6278

Yuan JH, Xua RK, Zhang H (2011) The forms of alkalies in the biochar produced from crop residues at different temperatures. Bioresour Technol 102:3488-3497

Zhang G, Hu M, He L, Fu P, Wang L, Zhou J (2013) Optimization of microwave-assisted enzymatic extraction of polyphenols from waste peanut shells and evaluation of its antioxidant and antibacterial activities in vitro. Food Bioprod Proc 91:158-160 